\title{
Rat models of high risk colorectal anastomoses ${ }^{1}$
}

Valter Alvarenga Junior', Edna Delabio Ferraz', Marcia Rolim", Amabile Marran Carra'", Pedro Teixeira da Silva"', Olavo Borges Franco"', Mariana Menegat Dias Cordeiro'I", Christina Maeda Takiya'" , Wagner Baetas-da-Cruz"I", José Eduardo Ferreira Manso'v, Manoel Luiz Ferreirav, José Marcus Raso Euláliov, Paulo César Silvav, Heitor Siffert Pereira de Souzavı, Alberto Schanaider ${ }^{\text {VII }}$

'Fellow PhD degree, Postgraduate Program in Surgical Sciences, Department of Surgery, School of Medicine, Universidade Federal do Rio de Janeiro (UFRJ), Brazil. Acquisition, analysis and interpretation of data; technical procedures.

"Fellow Master degree, Postgraduate Program in Surgical Sciences, Department of Surgery, School of Medicine, UFRJ, Rio de Janeiro-RJ, Brazil. Acquisition, analysis and interpretation of data; technical procedures.

I"'Graduate student, Department of Surgery, School of Medicine, UFRJ, Rio de Janeiro-RJ, Brazil. Technical procedures.

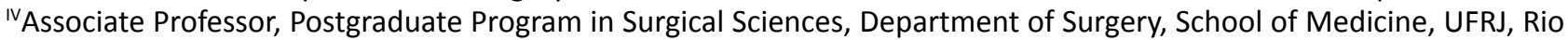
de Janeiro-RJ, Brazil. Analysis and interpretation of data, critical revision.

VPhD, Associate Professor, Department of Surgery, School of Medicine, UFRJ, Rio de Janeiro-RJ, Brazil. Analysis and interpretation of data, technical procedures.

${ }^{V}$ PhD, Full Professor, Experimental Surgical, Coordinator of Postgraduate Program in Medical Clinics, Department of Surgery, School of Medicine, UFRJ, Rio de Janeiro-RJ, Brazil. Intellectual, conception and design of the study; analysis and interpretation of data.

VIIPhD, Full Professor, Head, Centre of Experimental Surgical, Coordinator of Postgraduate Program in Surgical Science, Department of Surgery, School of Medicine, UFRJ, Rio de Janeiro-RJ, Brazil. Intellectual, conception and design of the study; analysis and interpretation of data; manuscript preparation; critical revision.

\section{Abstract}

Purpose: To evaluate the most frequent surgical techniques of high-risk colorectal anastomoses in rats.

Methods: Wistar rats were enrolled in three different models comprising inflammatory (TNBS enema), vascular (portal vein occlusion) or obstructive (a non-ischemic constricting ring) mechanisms associated with colonic anastomosis that had accomplished after these former lesions. Histological analyses (Hematoxylin and eosin and Picrosirius red) were performed.

Results: All anastomoses techniques were associated with risk factors and had complications, mainly anastomotic leakage. In Study 1, the use of a pharmacological agent, trinitrobenzene sulfonic acid (TNBS) mimicked an inflammatory bowel disease such as Crohn's disease with $50 \%$ of anastomosis leakage, the higher percentage among all models tested. In Study 2, after portal ischemia followed by reperfusion it was observed a dense neutrophil infiltrate in the midst of necrotic tissue and fibrin at the anastomotic site and 5 days after the anastomosis, no collagen was produced. In Study 3, 5 days after the mechanical obstruction some denuded areas of epithelium with marked oedema of mucosa and submucosa were seen, at the anastomotic site and anastomosis group showed some reduction of collagen density when compared with Control/Sham group.

Conclusion: All the experimental surgical techniques tested in rats were associated with high-risk colorectal anastomoses and were useful to study colonic anastomotic healing and intestinal leakage.

Key words: Colon. Anastomosis, Surgical. Models, Animal. Rats. 


\section{Introduction}

Treatment of high-risk colorectal anastomosis associated with intestinal leakage is still a challenge. The impact of anastomotic dehiscence on patient morbidity and quality of life is devastating, even when it is detected within the limit of 60 minutes, since such situation usually leads to fecal peritonitis and uncontrollable sepsis ${ }^{1}$. Many aspects including age, nourishment state, type and duration of disease, local and systemic conditions, use of some drugs, for instance, may influence how to handle properly those complications. Except for abdominal impairment due to inadequate surgical technique, inflammation is the main substrate of dehiscence in colonic anastomosis. However, otherpathophysiological mechanisms are frequently associated, including vascular or obstructive causes ${ }^{2}$.

The best surgical management to deal with acute left-colon inflammation, ischemia with peritonitis or obstruction is still controversial. Clearly, it is a difficult task to make a choice among several different modalities of treatment. Some surgeons may recommend temporary or permanent colostomy, a stage operation with a second step late reconstruction or even a second look. Nevertheless, others may advocate resection and direct anastomosis. Therefore, to deepen the studies with experimental models of highrisk anastomoses can improve the knowledge and help surgeons to make the best decision.

Experimental models give the researchers the opportunity to develop pilot experiments in severe conditions that are otherwise incompatible with human life and useful to provide or consolidate translational basis in future clinical studies.

In the last decades, several rat models of colorectal anastomosis have been tested to study intestinal leakage and standardize different techniques looking for the best alternative ${ }^{2-20}$. The heterogeneity seen in the different scenarios with regard to the evaluation of colonic healing limits the comparability among them and may explain the conflicting results reported. This manuscript has the aim to evaluate the most usual rat models utilized in the research line of the Postgraduate Program in Surgical Sciences, Department of Surgery, School of Medicine of UFRJ.

\section{Methods}

The study was in conformity to Brazilian law for scientific use of animals and international guiding principles for animal care and was approved by the Ethics Committee for Animal Research of UFRJ.

\section{Experimental design}

Adult isogenic Wistar rats (Rattus norvegicus albinus), weighing from 270 to $300 \mathrm{~g}$, were obtained from the Centre of Experimental Surgery, School of Medicine of UFRJ. They were housed in appropriate environmental conditions, on a circadian cycle in a temperature-controlled room $\left(25^{\circ} \mathrm{C}\right)$, fed with standard industrial rat chow and water $a d$ libitum.

\section{Shared surgical pre, peri and postoperative assessments}

All rats were subjected to 24 hours of food fasting before the operative procedure. The anesthetic procedure, whatever the operative procedure was, consisted of intraperitoneal administration of ketamine $(10 \mathrm{mg} / \mathrm{kg})$ and xylazine $(1 \mathrm{mg} / \mathrm{kg})$ solution. Immediately after anesthetic administration, animals were immobilized in the dorsal decubitus and the skin over the surgical site was shaved with chlorhexidine solution (chlorohex ${ }^{\circ}$ ). 
Animals were randomly assigned in three experimental studies, each one with three groups of animals as follow: Model 1- Control/Sham ( $n=10)$, Anastomosis ( $n=$ 10) and Anastomosis + TNBS intraluminal administration (enema), ( $n=12)$. Model 2Control/Sham ( $n=10)$, Anastomosis $(n=10)$ and Anastomosis + portal occlusion $(n=20)$. Model 3, Control/Sham ( $n=10)$, Anastomosis $(n=10)$, Anastomosis + mechanical obstruction (external ring), $(n=12)$.

To access the peritoneal cavity, a $3 \mathrm{~cm}$ long midline incision in the abdomen was done. An end to-end extramucosal technique in onelayer suture (6-0 polypropylene) was used in all anastomoses.

\section{Model 1 (TNBS)}

Colitis was induced by an intracolonic enema of $0.7 \mathrm{~mL}$ of a solution containing $20 \mathrm{mg}$ of 2,4,6-trinitrobenzene sulfonic acid (TNBS) (Sigma) in 35\% ethanol (Merck, Damstadt, Germany) using a rubber cannula ( $8 \mathrm{~cm}$ long) inserted through the rectum. After de enema, animals were maintained in the Trendelenburg position for one minute.

Seven days after the TNBS instillation, all animals were anesthetized as aforementioned and examined with a flexible fiberscope FB $120 \mathrm{P}$ with a diameter of $2.8 \mathrm{~mm}$ (Fujinon, Japan) assembled to a video camera for recording images. Two independent observers, using an adapted endoscopic index of colitis (3), scored the colonic injury analyzing the following parameters: hyperemia, number and size of vessels, bleeding, and mucous secretion, ranging from 0 to $4^{4}$.

Just after the colonoscopy, a colonic segment of $3 \mathrm{~cm}$ was removed and an endto-end extramucosal anastomosis in one-layer suture technique (6-0 polypropylene) was performed. Histologic analyses were done in the samples obtained at days 7 and 14 .

\section{Model 2 (Portal occlusion)}

After the portal vein identification, a non-traumatic microvascular clamp (AB-3, $S \& T^{\oplus}$ ) totally occluded this vein for $30 \mathrm{~min}$. Then the colon was cut and an end-to-end extramucosal anastomosis in a single suture line was done (Figure 1).

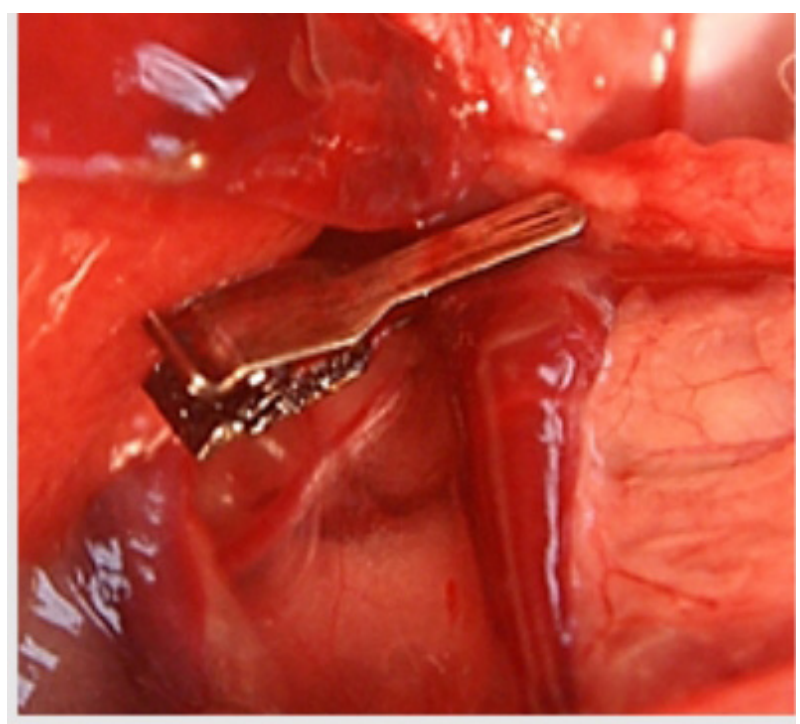

Figure 1 - Portal vein occlusion in rat. A micro clamp were placed proximally on the portal vein.

\section{Model 3 (Mechanical Obstruction)}

After the laparotomy, a ring of a polyethylene tube (diameter of $1.0 \mathrm{~cm}$ ), cut lengthwise, was placed around a segment of the distal colon, about $3-4 \mathrm{~cm}$ above peritoneal reflection, with a constricting but non-ischemic technique, preserving the integrity of the marginal vessel. Then the longitudinal cut of the ring was closed with a 5-0 nylon stitch. 24 hours later, a $10 \mathrm{~cm}$ segment comprising, in the middle, the anastomotic site was excised followed by an end-to-end one-layer extramucosal anastomosis (Figure 2). 

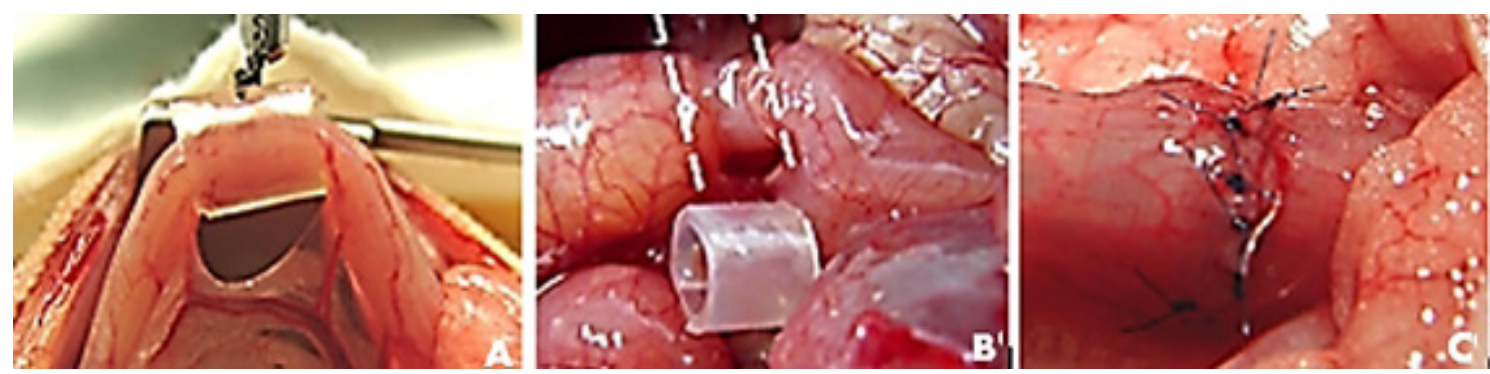

Figure 2-Obstruction of the distal colon in rat model. The ring was placed 3-4 $\mathrm{cm}$ above peritoneal reflection (A). $24 \mathrm{~h}$ after, with the removal of the ring, a segmental area encompassed by this device with a partial stenosis was resected (between the two dotted lines) (B). A finished anastomosis (C).

In the first two postoperative days, animals received analgesia with dipyrone $(1 \mathrm{~g} / \mathrm{L})$ in the drinking water. At the end of all experiments, groups of animals were killed with the anesthetic solution (4 times the original dose).

Samples from animals of the TNBS colitis, portal occlusion and obstruction group plus anastomosis were obtained, respectively, 14,5 and 5 days after the initial pharmacological or surgical intervention. In all three studies, the same interval was utilized for getting samples of the anastomosis group alone.

\section{Histological analyses}

Specimens were fixed in $40 \mathrm{~g} / \mathrm{L}$ formaldehyde saline, dehydrated in ethanol, embedded in paraffin, cut into serial sections of $5 \mu \mathrm{m}$, and finally submitted to Hematoxylineosin and Picrosirius-red staining procedures.

A double-blind histological analysis was performed under light microscopy by two independent observers. At least 10 different areas per tissue section were analyzed at $\mathrm{x} 4$ and $\mathrm{x} 10$ magnifications and images were captured (Leica Microsystems ${ }^{\circ}$, Switzerland).

In hematoxylin-eosin-stained, the following parameters were analyzed: inflammatory infiltrate in the lamina propria, mucosal and submucosal erosion, loss of intestinal epithelium, vascular congestion, number and depth of crypts, and goblet cells.
To assess the collagen deposition in the colon wall, phosphomolybdic acid-Picrosirius red dye (Sirius Red F3BA 0.1\%, Mobay Chemical Co, Pittsburgh, PA, EUA) was used to stain collagen fibers (reddish color). Samples were cut in serial paraffin sections of $5 \mu \mathrm{m}$. The quantification of the total collagen density was done calculating the area positively stained for collagen in relation to total intestinal tissue, with $x 4$ and $x 10$ magnifications, and using an imaging analysis system (Leica QWin Plus V 3.5.1, Leica Microsystems ${ }^{\circ}$, Switzerland).

\section{Statistics analyses}

Statistical analyses were performed using the software SPSS for Windows (Version 10.0.1, SPSS Inc., 1989-1999, USA). Oneway ANOVA test and Tukey-Kramer multiple comparison tests were used. The level of significance was set at $\mathrm{P}<0.05$.

\section{- Results}

A former study has been developed and showed that the results of the Control group were similar to the Sham group of rats.

In the Model 1, 50\% of the rats of the TNBS and anastomosis group had peritonitis with intestinal leakage and dehiscence. In the Model 2, 20\% of the rats of the portal occlusion followed by anastomosis group had suture dehiscence within the first 5 post- operative 
days. It was not seen any leakage or dehiscence of the anastomosis in the Model 3, however, $25 \%$ of the rats had microabscess around the suture line.

\section{Model 1 (TNBS enema)}

\section{Colonoscopy}

One week after TNBS induced-colitis, all animals that underwent only a colonoscopy showed intense hyperemia, an increase of the number and size of vessels, mucous secretion, a fragile mucosa with bleeding not only during the forward movement of the colonoscope but also at the insufflation time, coalescent ulcerations and some areas of necrosis (Figure 3). All animals had an endoscopic index score greater than 8 .
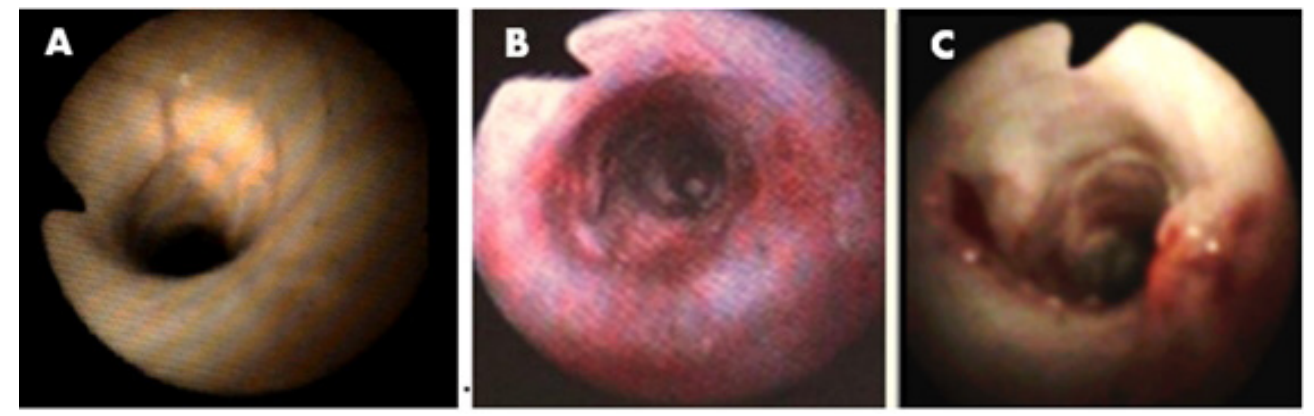

Figure 3 - Colonoscopy in rats. Control/Sham group (A). Intense bleeding and hyperaemia seven days after TNBS-induced colitis (B). Coalescent ulcerations with necrotic areas in animal with TNBS enema (C).

\section{Histology}

Control/Sham group presented an organized architecture with a mucosecretor epithelial lining (goblet cells) and standard images compatible with both normal pattern of lamina propria and muscular layers. In TNBS plus anastomosis group, the inflammatory lesions consisted of mucosal edema, inflammatory infiltrate, lymphoid follicular hyperplasia, vascular congestion, decreased number of crypts, expansion of cell elements of lamina propria and evidence of transmural inflammation. In the area of the anastomosis, there were ulcerations of varied size and it was seen an apparent gap of the mucosa between the edges of the surgical incision, demonstrating a delay in the healing process. The anastomosis group of animals displayed less inflammatory process directly related to the surgical trauma per se and a healing process compatible with the results usually expected (Figure 4).

Quantitative analyses of the collagen density in the colon of rats only with anastomosis showed a less intense fibrosis than that found in TBNS-colitis and anastomosis group $(P<0.001)$ (Figure 4$)$.
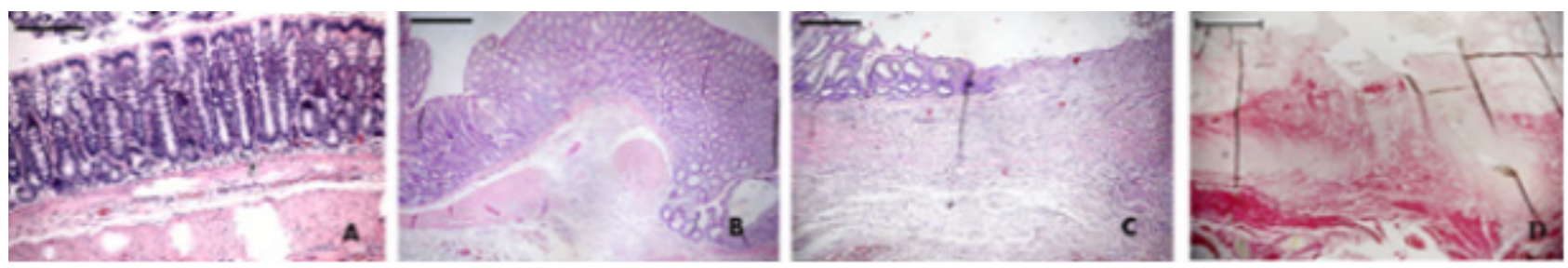

Figure 4 - Hematoxylin and eosin in rat's colon. Control group (A). Anastomosis group at $14^{\text {th }}$ postoperative day of the wound healing (B). TNBS and anastomosis group showed a delayed in the healing process (C). In TNBS and anastomosis group stained with Picrosirius red it was seen an intense inflammation and fibrosis reduction. A severe separation and disorganization of the muscle fibres was also observed (D). x10 magnification. Scale bar, $100 \mu \mathrm{m}$. 
Model 2 (Portal vein occlusion)

\section{Histology}

In the anastomotic region, $24 \mathrm{~h}$ after the surgical procedure, it was seen deposition of fibrin at the edges of the wound with a moderate presence of neutrophils without collagen formation. Five days after, wound space was filled with provisional matrix, rich in collagen fibers and oriented fibroblasts. In portal occlusion and anastomosis group, after $24 \mathrm{~h}$, a dense neutrophil infiltrate with deposition of fibrin was observed. Five days after, in the same group, the anastomotic borders were still separated and the space between these edges was partially filled by neutrophils, fibrin and necrotic material without tissue repair (Figure 5).
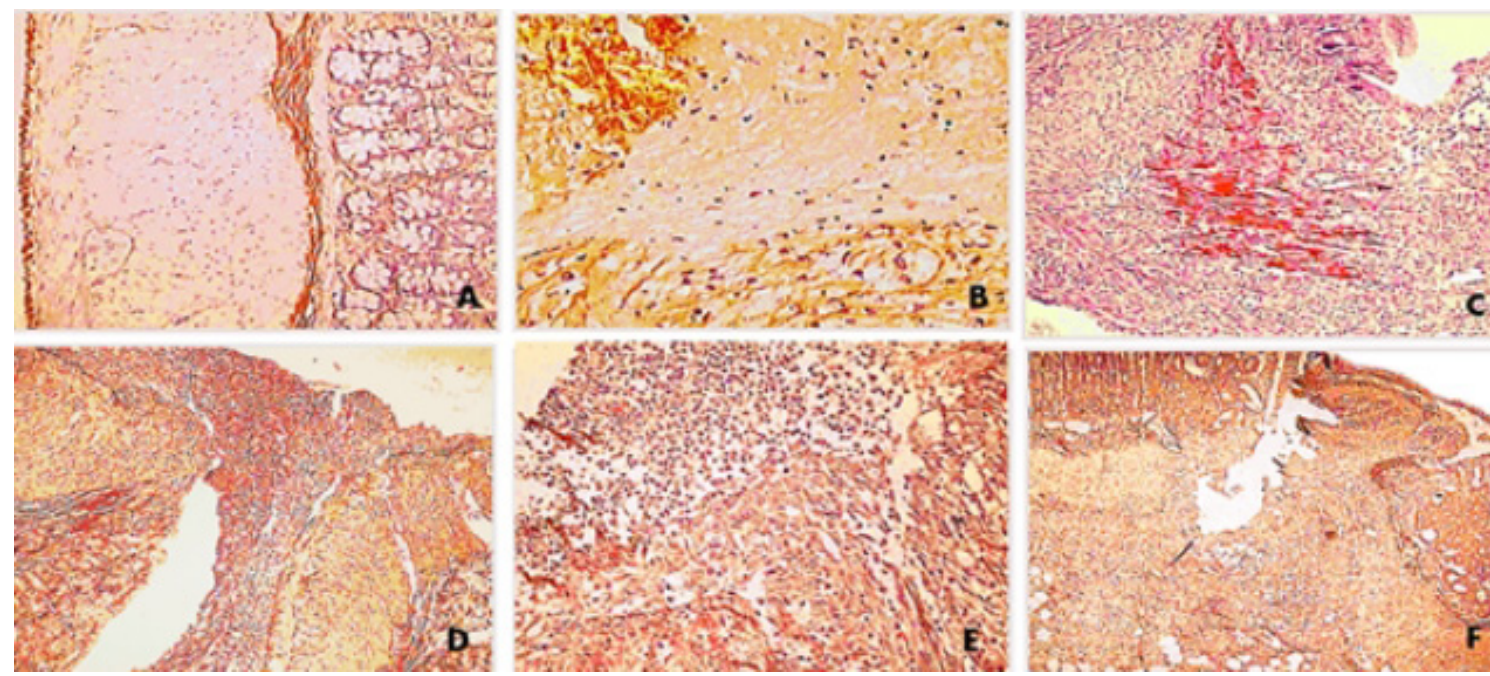

Figure 5 - Picrosirius staining of the rat colon. Findings compatible with colonic normality, $\times 10$ magnification (A). Rats of anastomosis group after 24 hours showed between the anastomosis edges moderate inflammation filled with fibrin, $x 10$ magnification (B). In the same group, on day 5, an expressive synthesis of collagen, forming parallel bridges inside the incision space was developed, $x 4$ magnification $(C)$. In portal vein occlusion and colonic anastomosis group, after $24 \mathrm{~h}$ a severe unspecific inflammatory reaction was seen, $\mathrm{x} 4$ magnification (D). In the same group, on day 5, collagen production was not found and the edges of the surgical wound were still separated by an area partially filled with neutrophils, fibrin and necrotic debris, x10 magnification (E) and $x 4$ magnification (F).

\section{Model 3 (Mechanical obstruction)}

\section{Histology}

In the group with anastomosis after obstrucion stained with Hematoxylin and eosin, there were some denuded areas of epithelium with intense submucosal edema and gaps in the epithelium and muscularis propria. A severe granulation tissue was observed in the lamina propria and, mainly, in the anastomosis site. At the edges of the incision the epithelium with regenerative characteristics stand out, but there was no regeneration of muscularis propria (Figure 6).

Group anastomosis showed the lowest collagen density, with significant reduction compared to the Sham/Control group $(P=0.05)$. There were no differeces in collagen density when compared to obstruction followed by anastomosis group with the Control/Sham one (Figure 6). 


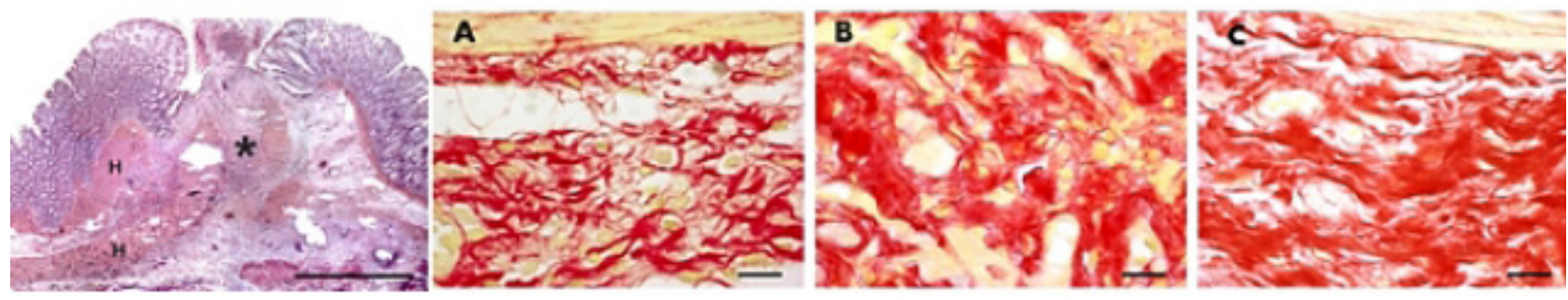

Figure 6 - Histology of rats colon. In obstrucion and anastomosis group (H\&E), in the proximal stump of the point of obstruction an important hypertrophy of the muscular layers of the mucosa and muscularis propria was seen $(H)$. A necrotic focus showed gaps from the epithelium untill the muscularis propria $\left({ }^{*}\right), x$ 4 magnification. Scale bar $100 \mu \mathrm{m}$. In Picrosirius stained samples (A,B and C), anastomotic group showed a collagen (red color) density reduction (A) compared with obstruction plus anastomosis group (B) and Sham/ Control group, $\mathrm{x} 4$ magnification. Scale bar $20 \mu \mathrm{m}$.

\section{- Discussion}

One of the major concerns of surgeons who deal with colonic anastomosis is the leakage with peritonitis and sepsis. It is noteworthy that the mortality rate in consequence of this complication may exceed $20-30 \%{ }^{2}$. Several causes may be enrolled, but most frequently, an acute inflammatory process, local vascular problems and an obstructive condition are the main causes which usually require a surgical approach. Moreover, to estimate the risk of leakage, even after the inspection and management of the operative field, is still a challenge.

Some limitations using rats' models to create clinical intestinal leakage have been commonly reported, like the necessity of radical interventions and difficulty to simulate intraabdominal sepsis as seen in human beings. However, most animals with complications in the anastomotic site have a quite similar outcome, sometimes with signs of abscess and in other occasions with generalized peritonitis and death, if not properly treated. These findings were seen in our group of rats. Our data suggest that the model with pharmacological induction of colitis associated with anastomosis is more likely to develop leakage around the suture line than the vascular and obstructive ones (50\% vs. $20 \%$ vs. $0 \%$, respectively).
Obviously, clinical signs and symptoms of an acute abdomen are more evident in human's patients than in animal models. In rats, most of the time, death comes before any diagnosis of peritonitis or sepsis.

Because anastomotic leakage generally occurs within the first week after surgery, all three studies were limited up to this interval after the anastomosis had been performed.

TNBS-induced colitis is one of the most common models of experimental colitis. The colonic mucosa is exposed to the contactsensitizing agent, trinitrobenzene sulfonic acid, a covalently reactive compound that attaches to autologous proteins and stimulates a delayed-type hypersensitivity response to the hapten-modified self-antigens ${ }^{3,4}$. Our group has begun to experiment with TNBS as an etiological agent of experimental colitis almost 10 years ago. Since then, this drug has been tested by our research group, successfully ${ }^{5-8}$.

In Model 1, colonoscopy was utilized in order to confirm the presence and the severity of colitis individually. The results were uniform and all animals had colonic signs of a relevant colitis, validating the experimental model. Moreover, this is an excellent model of inflammatory bowel disease in rat since displays several features consistent with those observed in humans, like in Crohn's disease ${ }^{6}$.

In Model 2 the histological findings 
showed a severe inflammatory process in animals of TNBS and anastomosis group. Beside the inflammation due to the anastomosis itself, TNBS-colitis caused the release of metalloproteinases inhibitors, which activate the collagen deposition by the myofibroblasts and fibroblasts in the extracellular matrix of the intestinal mucosa, contributing to the formation of intestinal fibrosis.

Vascular occlusion, as performed in Model 2, is a huge problem not only by the impairment of blood supply, but also by the release of humoral mediators, especially if there is reperfusion. Jansen-Winkeln et al. ${ }^{9}$ studying the Pringle maneuver in rats showed that such strategy could weaken the bowel anastomoses healing. They found a higher mortality of the animals because of an increased risk of anastomotic leakage after colonic resection. It is well known that venous portal or mesenteric obstruction followed by reperfusion trigger a huge burst of oxygen-derived free radicals producing deleterious effects on the healing processes of anastomotic wound in the intestinal wall ${ }^{10-12}$. Besides, oxidative stress may worsen the former lesions with local and systemic effects ${ }^{10,11}$.

In the present study, the portal occlusion with an ischemic period of 30 minutes was chosen because it has been shown in rats that venous stasis over $30 \mathrm{~min}$ of mesenteric clamping could cause high rates of mortality of the animals. This information was similar to that found by Simsek et al. ${ }^{11}$ after portal triad occlusion, lasting more than 30 minutes. They described the damage of anastomotic healing of the left colon with higher mortality rate. Sébe et al. ${ }^{12}$ also studied the effects of clamping the hepatic pedicle in small and large bowels and observed the same mucosal damage as we did. Thirty minutes after release of the hepatic pedicle clamping it was observed the detachment of the epithelium at the top of the intestinal villi and the presence of hemorrhage with intense leukocyte infiltration. Yano et al. ${ }^{13}$ working with rats after venous occlusion verified that damage resulting from both splanchnic congestion and degree of intestinal lesion was greater than those in consequence of arteriovenous or arterial occlusion per se.

In Model 2, the group of rats submitted only to colonic anastomosis had some fibroblast and collagen deposition, respectively, $24 \mathrm{~h}$ and 5 days after the anastomosis. However, even after 5 days, portal occlusion plus anastomosis group of rats had no collagen production. Hence, the result of venous stasis gave rise to a healing process impairment without collagen synthesis, predisposing to anastomotic dehiscence, as seen in five rats (20\%), with two occurrences within the first $24 \mathrm{~h}$ and another three in a period up to 5 days ${ }^{10}$. Our results showed that portal occlusions model could be an effective model of high risk anastomosis.

In Model 3, obstruction was induced by a constricting non-ischemic ring applied 24-h before anastomosis. Sky et al. ${ }^{14}$ described a similar technique to achieve a colonic obstruction in rats, successfully. Törnqvist et al. ${ }^{15}$ after resection of left-colon stenosis in Wistar rats, similarly, analyzed the collagen metabolism on anastomotic healing. The authors found an increased complication rate in the stenosis group (using ring tube) when compared with the control one (27 percent vs. 2 percent) but did not show differences in the collagen turnover. One possible explanation for the presence of anastomotic complication after obstruction could be the increased fecal bulk and bacterial load in the lumen upstream ${ }^{13}$. Regarding to the dosage of hydroxyproline, Bezuti et al. ${ }^{16}$, after performing in Wistar rats a 4 days obstruction at rectosigmoid junction followed by 3 days of anastomosis, confirmed the same results as Törnqvist and our research did. Bezuti et al. ${ }^{16}$, observed a similar collagen deposition in the anastomotic area when anastomosis plus obstruction group was 
compared with Control/Sham group.

Concerning to anastomosis group alone, a marked reduction of collagen concentration in the left colon, extending proximally was found. Jibons et al. ${ }^{17}$ showed the same findings at the first 4 to 7 postoperative days and they also highlight an increased breakdown (lysis) of collagen. Likewise, Blomquist et al. ${ }^{18}$ studying the collagen synthesis after a lowresidue diet in anastomosis group of rats noticed a reduction of collagen deposition and concluded that relative bowel rest diminishing fecal loading could have positive significance implying in the colonic healing. Braskén et al. ${ }^{19}$ theorized that if a normal colon of rats usually has a strong aerobic and anaerobic glycolytic metabolism, the anastomosis could cause a long-lasting reduction in the energy metabolism, especially in the mucosa and the muscle layers, contributing to weakening the anastomotic repair. Moreover, one of the most acceptable explanation is that sutures of a colon anastomosis lost the most collagen presumably through activation of metalloproteinases expression $^{20}$.

\section{Conclusion}

Three animal models in rats are reproducible, mimic human complications and may be useful not only to evaluate pathophysiological mechanism but also to test preventive measures aiming to reduce the leakage in high risk anastomoses.

\section{References}

1. Stergios K, Kontzoglou K, Pergialiotis V, Korou LM, Frountzas M, Lalude O, Nikiteas N, Perrea DN. The potential effect of biological sealants on colorectal anastomosis healing in experimental research involving severe diabetes. Ann R Coll Surg Engl. 2017 Mar;99(3):189-92. PMID: 27917665.

2. Platell C, Barwood N, Dorfmann G, Makin G. The incidence of anastomotic leaks in patients undergoing colorectal surgery. Colorectal Dis. 2007 Jan;9(1):71-9. PMID: 17181849.

3. Belmiro CL, Castelo-Branco MT, Melim LM, Schanaider A, Elia C, Madi K, Pavão MS, de Souza HS. Unfractionated heparin and new heparin analogues from ascidians (chordate-tunicate) ameliorate colitis in rats. J Biol Chem. 2009 Apr 24;284(17):11267-78. PMID: 19258310.

4. Alvarenga V Jr, Pacheco RG, Esposito CC, Buongusto $\mathrm{F}$, Castelo-Branco MT, Madi K, Belmiro CR, Pavão MS, de Souza HS, Schanaider A. Ascidian (chordate-tunicate) and mammalian heparina enemas attenuate experimental diversion colitis. Surgery. 2014 Feb;155(2):217-27. PMID: 24287143.

5. Carvalho AT, Souza H, Carneiro AJ, CasteloBranco M, Madi K, Schanaider A, Silv F, Pereira Junior FA, Pereira MG, Tortori C, Dines I, Carvalho J, Rocha E, Elia C. Therapeutic and prophylactic thalidomide in TNBSinduced colitis: synergistic effects on TNFalpha, IL-12 and VEGF production. World J Gastroenterol. 2007 Apr 21;13(15):2166-73. PMID: 17465495.

6. Belmiro CLR, Castelo-Branco MTL, Melim LMC, Schanaider A, Elia C, Madi K, de Souza HSP. Unfractionated heparin and new heparin analogues from ascidians (chordatetunicate) ameliorate colitis in rats.J Biol Chem. 2009 Apr 24;284(17):11267-78. PMID: 19258310.

7. Castelo-Branco MT, Soares ID, Lopes DV, Buongusto $F$, Martinusso CA, do Rosario A Jr, Souza SA, Gutfilen B, Fonseca LM, Elia C, Madi K, Schanaider A, Rossi MI, Souza HS. Intraperitoneal but not intravenous cryopreserved mesenchymal stromal cells home to the inflamed colon and ameliorate experimental colitis. PLoS One 2012;7(3):e33360. PMID: 22432015.

8. Marques CC, Castelo-Branco MT, Pacheco RG, Buongusto $F$, do Rosário $A \mathrm{Jr}$, Schanaider A, Coutinho-Silva R, de Souza HS. Prophylactic systemic P2X7 receptor blockade prevents experimental colitis. Biochim Biophys Acta. 2014 Jan;1842(1):6578. PMID: 24184714.

9. Jansen-Winkeln B, Tagkalos E, Heimann A, Gaiser T, Hirsch D, Gockel I, Mittler J, Lang $\mathrm{H}$, Heinrich S. Pringle maneuver increases the risk of anastomotic leakage after 
colonic resection in rats. HPB (Oxford). 2018 May;20(5):392-97. PMID: 29306581.

10. Rolim MF, Riger CJ, Eleutherio EC, Colão C da F, Pereira GC, Schanaider A. Colonic healing after portal ischemia and reperfusion: an experimental study with oxidative stress biomarkers. Redox Rep. 2007;12(6):267-74. PMID: 17961298.

11.Simsek A, Yagci G, Zeybek N, Gorgulu S, Kaymakcioglu N, Kesim E, Akdeniz A, Ozmen MM, Renda N. Effects of portal triad occlusion on left-sided colonic anastomosis. Int Surg. 2002 Jan-Mar;87(1):25-30. Erratum in: Int Surg. 2003 Apr-Jun;88(2):121. PMID: 12144186.

12.Sébe AA, Nigro AJT, Gomes PO, Simões MJ. Efeitos do clampeamento do pedículo hepático nos intestinos. Acta Cir Bras. 2000 Jan-Mar;15(1). doi: 10.1590/S010286502000000100001.

13. Yano K, Hata Y, Matsuka K, Ito O, Matsuda $\mathrm{H}$. Time limits for intestinal ischemia and congestion: an experimental study in rats. Ann Plast Surg. 1994 Mar;32(3):310-4. PMID: 8192394.

14.Syk I, Mirastschijski U, Jeppsson BW, Agren MS. Experimental colonic obstruction increases collagen degradation by matrix metalloproteinases in the bowel wall. Dis Colon Rectum. 2003 Sep;46(9):1251-9. PMID: 12972971.

15.Törnqvist $A$, Blomquist $P$, Jiborn $H$, Zederfeldt B. Anastomotic healing after resection of left-colon stenosis: effect on collagen metabolism and anastomotic strength. An experimental study in the rat. Dis Colon Rectum. 1990 Mar;33(3):217-21. PMID: 2311466.

16. Bezuti MT, Féres $O$, Campos AD, Aprilli F, Rocha JJR, Garcia RS, Joviliano OFD. Cicatrização de anastomoses colônicas na vigência de obstrução intestinal: estudo experimental em ratos. Acta Cir Bras. 2002 Aug;17(Suppl. 3):109-15. doi: 10.1590/ S0102-86502002000900023.

17.Jiborn $\mathrm{H}$, Ahonen J, Zederfeldt B. Healing of experimental colonic anastomoses. III. Collagen metabolism in the colon after left colon resection. Am J Surg. 1980 Mar;139(3):398-405. doi: 10.1016/00029610(80)90302-5.

18. Blomquist $\mathrm{P}$, Ahonen J, Jiborn $\mathrm{H}$, Zederfeldt $B$. The effect of relative bowel rest on healing of colonic anastomoses. Collagen synthesis and content in the colonic wall after left colon resection and anastomosis in the rat. Acta Chir Scand. 1984;150(8):677-81. PMID: 6532042.

19.Braskén P. Healing of experimental colon anastomosis. Eur J Surg Suppl. 1991;(566):151. Review. PMID: 1725603.

20.Agren MS, Andersen TL, Mirastschijski U, Syk I, Schiødt CB, Surve V, Lindebjerg J, Delaissé $\mathrm{JM}$. Action of matrix metalloproteinases at restricted sites in colon anastomosis repair: an immunohistochemical and biochemical study. Surgery. 2006 Jul;140(1):72-82. PMID: 16857445.

\section{Correspondence:}

Alberto Schanaider

Centro de Cirurgia Experimental, UFRJ

Avenida Carlos Chagas Filho, 373/Bloco J, 2ㅇ andar

21941-902 Rio de Janeiro - RJ Brasil

Tel.: (55 21)3938-6549

albertoscha@gmail.com

Received: June 29, 2018

Review: Aug 25, 2018

Accepted: Sept 26, 2018
Conflict of interest: none

Financial sources: FAPERJ, CAPES, and CNPq

\begin{abstract}
${ }^{1}$ Research performed at Center of Experimental Surgical, Postgraduate Program in Surgical Science, Department of Surgery, School of Medicine, Universidade Federal do Rio de Janeiro (UFRJ), Brazil. Part of PhD and Master degree theses, Postgraduate Program in Surgical Science. Tutor: Prof. Dr. Alberto Schanaider.
\end{abstract}

